\title{
Impaired non-esterified fatty acid suppression to intravenous glucose during late pregnancy persists postpartum in gestational diabetes: a dominant role for decreased insulin secretion rather than insulin resistance
}

Received: 15 December 2004 / Accepted: 22 February 2005 / Published online: 7 June 2005

C) Springer-Verlag 2005

\begin{abstract}
Aims/hypothesis: Non-esterified fatty acids are implicated in the pathogenesis of gestational (GDM) and type 2 diabetes. We examined the relationship between NEFA dynamics, insulin resistance and beta cell dysfunction in women with GDM in late pregnancy and postpartum. Methods: A total of 19 Caucasian women with GDM and 19 healthy pregnant women matched for BMI and age underwent an IVGTT in the third trimester and 4 months postpartum, deriving values for insulin sensitivity (SI), insulin secretion (AIRg) and disposition index (DI). NEFA levels were measured serially. Results: In pregnancy, the GDM women had similar SI but reduced AIRg and DI compared with control subjects. The GDM group demonstrated significantly slower NEFA suppression, which was attributable to the GDM women who required insulin during pregnancy $(n=7)$ and who had markedly reduced AIRg and $K_{\text {NEFA }}$ (NEFA disappearance constant) compared with their matched controls. In contrast, GDM subjects not requiring insulin $(n=12)$ had similar NEFA suppression curves and AIRg to control subjects. Postpartum, GDM subjects demonstrated reduced SI and DI. The impaired suppression of NEFA persisted postpartum, but again only in the subgroup of GDM subjects who had required insulin during pregnancy. Furthermore, $K_{\mathrm{NEFA}}$ correlated with
\end{abstract}

K. A. McLachlan · F. P. Alford

Department of Endocrinology and Diabetes,

St Vincent's Hospital,

Fitzroy, Australia

\section{R. Boston}

Biomathematics and Biostatistics Clinical Studies,

New Bolton Center, School of Veterinary Medicine,

University of Pennsylvania,

West Chester, PA, USA

K. A. McLachlan $(\bowtie)$

St Vincent's Hospital,

PO Box 2900 Fitzroy, 3065, Australia

e-mail: mclachk@svhm.org.au

Tel.: +61-3-92883575

Fax: $+61-3-92883590$
AIRg and DI in both states, but not with SI. Conclusions/ interpretation: Impaired NEFA suppression occurs in GDM subjects both in late pregnancy and postpartum in response to IVGTT-induced endogenous insulin secretion. The impaired NEFA suppression is present in GDM women with the most severe beta cell dysfunction (who had required insulin during pregnancy) and is related to their insulin secretory dysfunction rather than their reduced SI.

Keywords Beta cell dysfunction - Gestational diabetes Insulin resistance $\cdot$ Non-esterified fatty acids · Pregnancy

Abbreviations AIRg: acute insulin response - DI: disposition index - GDM: gestational diabetes $\cdot K g$ : glucose disappearance constant $\cdot K_{\mathrm{NEFA}}$ : NEFA disappearance constant $\cdot K_{\mathrm{NEFA} / \mathrm{INS}}$ : NEFA disappearance constant/insulin release 0 to $40 \mathrm{~min} \cdot$ SI: insulin sensitivity

\section{Introduction}

Gestational diabetes (GDM) is associated with adverse maternal and perinatal outcomes, and carries an increased risk for the mother of subsequently developing type 2 diabetes [1]. The pathophysiology of GDM is thought to involve a combination of increased insulin resistance and beta cell dysfunction. Insulin secretion is low for the level of insulin resistance, i.e. reduced disposition index (a measure of insulin secretion corrected for the prevailing insulin resistance) [2]. These defects persist postpartum $[3,4]$.

Fasting NEFA levels during pregnancy are known to correlate with insulin resistance as measured by a hyperinsulinaemic clamp [5]. This has led to the suggestion that, chronically, they may have an impact on insulin resistance in pregnancy [6]. GDM women have demonstrated abnormalities in lipid metabolism in addition to their glucose intolerance, e.g. elevated fasting NEFA levels compared with normoglycaemic controls [7] and impaired suppression of NEFA during an acute exogenous insulin infusion [5]. Elevated NEFA levels are also implicated in 
the pathogenesis of type 2 diabetes and are an independent predictor of the development of type 2 diabetes in at-risk populations [8]. Acute and chronic NEFA infusion reduces insulin-stimulated glucose uptake [9]. The effect of NEFA on insulin secretion is less clear, with both enhancement $[10,11]$ and inhibition $[12,13]$ reported. A recent study highlighted the susceptibility of the beta cell to NEFA in subjects genetically predisposed to diabetes, adding further weight to the role of NEFA in the development of type 2 diabetes [10]. As former GDM subjects are at high risk of diabetes, they represent an ideal population to study the relationship between NEFA abnormalities and early defects in insulin secretion and action.

We sought, therefore, to test the following: (1) whether NEFA dynamics were different in GDM compared with in control subjects, in and out of pregnancy, and (2) whether these differences could be related to the known defects in insulin secretion and action in GDM subjects. To this end we employed the frequently sampled IVGTT in the third trimester and 4 months postpartum in GDM women and in healthy pregnant women matched for BMI and age to assess NEFA dynamics after the glucose load.

\section{Methods}

Subjects Subjects were recruited from the obstetric clinics of the Mercy Hospital for Women and the Box Hill and Werribee Mercy Hospitals in Melbourne, Victoria, Australia. Nineteen women with GDM as diagnosed by the Australasian Diabetes in Pregnancy Society criteria [14] at their 28-week OGTT (75-g OGTT: fasting glucose $>5.5$ $\mathrm{mmol} / \mathrm{l}$; 2-h glucose $>8.0 \mathrm{mmol} / \mathrm{l})$ were recruited. All were negative for glutamic acid decarboxylase antibodies, except one subject who had a normal OGTT postpartum. Nineteen control women, pair matched for BMI $( \pm 4 \mathrm{~kg} /$ $\left.\mathrm{m}^{2}\right)$ in the third trimester and age ( \pm 4 years), and with no first-degree relative with diabetes and no history of polycystic ovarian syndrome or GDM, were also recruited. Subjects were studied in the third trimester of pregnancy (mean of 34 weeks gestation) and 4 months postpartum. An additional GDM subject and a matched control subject were studied postpartum, as this GDM subject refused testing during pregnancy (therefore $n=20$ for the postpartum studies). Of the 40 subjects, 37 were Caucasian and three had Mediterranean background. Eighteen of the 20 control subjects breastfed postpartum, compared with 14 of the 20 GDM subjects. Six control women were taking the progesterone-only pill, and one was taking the combined contraceptive pill; of the GDM women, four were on progesterone-only preparations and one was on the combined pill. These differences were not statistically significant. The studies were approved by the Research and Ethics Committees of the hospitals involved, and all subjects gave informed written consent.

Experimental design At 28 weeks of gestation, and 6-9 weeks postpartum, the women underwent a fasting standard 75-g OGTT. For the IVGTT the women fasted from
22.00 hours, having consumed three meals of more than $40 \mathrm{~g}$ carbohydrate the day previously. The subjects on an evening dose of intermediate-acting insulin during pregnancy ( $n=6$; Protaphane, Novo Nordisk, Denmark) were instructed to take two-thirds of their normal evening dose, as, for ethical reasons, we did not feel justified in omitting their evening insulin dose. A residual of that evening dose may have still been present the next morning, but should not have affected the calculation of insulin sensitivity or secretion by Minmod [15]. On arrival, the subjects were weighed and rested in a bed or chair, and a vein in the antecubital fossa was cannulated (Insyte 18 gauge; Becton Dickinson, Sydney, Australia). In the postpartum studies, WHR and percentage fat by bioimpedance were also measured. After resting, fasting blood was taken, and then $0.3 \mathrm{~g} / \mathrm{kg}$ of $50 \%$ dextrose was diluted by adding half saline and administered intravenously over 1 min [16]. A maximum dose of $20 \mathrm{~g}$ was used during pregnancy (in order to avoid overestimation of the glucose dose based on a late pregnancy weight), and $25 \mathrm{~g}$ was the maximum dose postpartum, which achieves maximal beta cell stimulation [17]. Samples were drawn from the same cannula at 2, 3, $4,6,8,10,15,20,30,40,60,75,90$ and $120 \mathrm{~min}$, with flushing of the cannula with $3 \mathrm{ml}$ of normal saline between each draw [16]. Samples were placed into pre-chilled tubes containing $4 \%$ sodium fluoride, $50 \mu \mathrm{l} / \mathrm{ml}$ blood (for glucose and insulin) or EGTA and reduced glutathione (for NEFA). They were then centrifuged within $40 \mathrm{~min}$ and stored at $-20^{\circ} \mathrm{C}$ until time of assay.

Methods Plasma glucose was analysed by a glucose oxidase method employing a YSI 1500 Sidekick analyser (Yellow Springs Instrument Company, Yellow Springs, $\mathrm{OH}, \mathrm{USA}$ ), CV $2.4 \%$. Insulin was measured with a radioimmunoassay [18], with less than $1 \%$ cross reactivity to proinsulin. Insulin antibodies were not present in any sample. The interassay CVs are $8.7 \%$ at insulin level 6 $\mathrm{mU} / 1,4.3 \%$ at $20 \mathrm{mU} / 1$ and $3.5 \%$ at $30 \mathrm{mU} / \mathrm{l}$. NEFA were measured using a Wako colorimetric kit (Wako Pure Chemicals, Osaka, Japan), with interassay CVs of 8, 11 and $13 \%$ for NEFA levels $1.2,0.7$ and $0.1 \mathrm{mmol} / \mathrm{l}$ respectively. Acute insulin response (AIRg) and insulin sensitivity (SI) were calculated using Minmod [15]. Disposition index (DI) is the product of SI and AIRg and represents an assessment of insulin secretion corrected for the prevailing insulin sensitivity [2]. Kg (glucose disappearance constant) is the absolute value of the slope of the regression line relating the natural log of glucose levels to time $10-40 \mathrm{~min}$, multiplied by 100 . The AUC for insulin 40-120 min and for NEFA 60-120 min was calculated using the trapezoid method. Our frequently sampled IVGTTs only continued for $120 \mathrm{~min}$ for the comfort and social needs of the women, so the basal values for glucose and insulin were used to create a 180 -min time point. This methodology has been shown to be valid in insulin-sensitive individuals [19]. To confirm its validity in insulin-resistant subjects, ten subjects were tested before and after induction of severe insulin resistance by administration of dexamethasone [20]. Comparable SI values 
were estimated with the extrapolated or actual 180-min data points, both in the pre- $(r=0.96, p<0.001)$ and post$(r=0.98, p<0.001)$ dexamethasone studies (mean differences: $-0.14 \pm 0.17[\mathrm{mU} / 1]^{-1} \times 10^{-4}$, and $-0.10 \pm 0.14[\mathrm{mU} / 1]^{-1} \times$ $10^{-4}$ ) and there was no error bias.

$K_{\text {NEFA }}($ NEFA disappearance constant) was calculated as the slope of the regression line relating the $\log _{e}$ of NEFA levels to time 15-40 min, multiplied by 100 . NEFA levels do not begin to decrease until at least $10 \mathrm{~min}$, and they reach a nadir between 40 and $90 \mathrm{~min}$. The period 1540 min was therefore selected as being the most representative of the decay of NEFAs; log NEFA 15-40 min is linear.

The NEFA suppression per unit of insulin secreted was also calculated as an insulin-corrected parameter, $K_{\mathrm{NEFA} / \mathrm{INS}}$, based on observations that insulin suppression of lipolysis is linear over the insulin dose range of $0-40 \mathrm{mU} / 1[21,22]$, and that interstitial concentration of insulin is within this range in the first $40 \mathrm{~min}$ of a $0.3-\mathrm{g} / \mathrm{kg}$ glucose IVGTT (the concentration of insulin in the interstitial fluid being the actual signal for a cellular insulin-dependent event) [23].

\section{$K_{\mathrm{NEFA} / \mathrm{INS}}=$}

$K_{\mathrm{NEFA}} /$ the incremental AUC for insulin 0 to $40 \mathrm{~min}$

$$
\times\left(\min ^{-1} \cdot \mathrm{mU}^{-1} \cdot 1\right) \text {. }
$$

Statistical analysis During pregnancy and postpartum, parameters of the GDM and control groups were compared using paired $t$-tests with normalisation of data by transformation where appropriate. NEFA suppression was analysed by comparison of the linearised log NEFA levels from 15 to $40 \mathrm{~min}$, using regression to test for differences in the slopes of GDM and control subjects. The linearised log glucose levels (i.e. $K g$ ) were tested in a similar way. To identify metabolic parameters associated with $K_{\text {NEFA, Spearman }}$ correlations were used. Then, to address the question of whether these associations were different in GDM and control subjects, regression was performed on the transformed normalised data to look for a difference in the slopes of the relationships between these groups. In addition, multiple regression, with transformation and normalisation of the data where appropriate, was used to determine the independent predictors of $K_{\mathrm{NEFA}}$. In order to identify differences between the insulin- and diet-treated GDM subjects and their matched control subjects, and between the two, Wilcoxon signed rank tests were used (because of the smaller numbers involved) with the Bonferroni correction applied due to the dual analysis of data (therefore $p<0.025$ for these analyses). The statistical software used was Minitab (Release 13; Minitab, State College, PA, USA) and Stata (version 8.02; StataCorp, College Station, TX, USA). Data are expressed as means (SD), or medians (interquartile range) for non-parametric data. A $p$ value of less than 0.05 was considered significant.

\section{Results}

Studies in late pregnancy

Baseline characteristics The two groups were well matched for BMI and age (Table 1).

Insulin sensitivity and secretion Results are shown in Table 2. The GDM subjects had similar SI to the control group. Their AIRg was significantly reduced, indicating a reduction in beta cell function of almost $45 \%$. SI was not significantly associated with fasting NEFA $(r=-0.29, p=$ 0.08 ) but was inversely associated with the minimum suppressed NEFA level $(r=-0.34, p=0.03)$.

NEFA suppression Results are shown in Fig. 1a. Regression analysis of the multiple-sampled NEFA curves demonstrated a significant difference between GDM and control subjects over time $(p<0.01)$, with GDM subjects having slower suppression of NEFA. The $K_{\text {NEFA/INS }}$ was similar in the two groups, indicating equivalent NEFA disappearance per unit rise of insulin released (Table 2).

In order to address our second aim, of identifying the metabolic factors associated with $K_{\text {NEFA }}$, we performed univariate correlations in all subjects. $K_{\mathrm{NEFA}}$ was correlated with measures of insulin secretion (AIRg: $r=0.45, p=$ 0.004 , DI: $r=0.60, p<0.001$ ), adiposity (BMI: $r=-0.38$, $p=0.01)$ and glucose tolerance $(K g: r=0.46, p=0.003$, fasting glucose in OGTT: $r=-0.56, p=0.01)$. In contrast, $K_{\text {NEFA }}$ was not significantly associated with SI $(r=0.29$, $p=0.09)$. With linear regression, with $K_{\mathrm{NEFA}}$ as the de-
Table 1 Baseline characteristics of the control and GDM subjects including glucose levels during OGTT (at 28 weeks gestation and 6 weeks postpartum)

Data are presented as means \pm SD or medians (interquartile range) as appropriate ${ }^{\mathrm{a}} p=0.03$, GDM vs controls ${ }^{\mathrm{b}} p<0.01$, GDM vs controls

\begin{tabular}{lllll}
\hline & \multicolumn{3}{l}{ Pregnancy } & \multicolumn{2}{l}{ Postpartum } \\
\cline { 2 - 3 } \cline { 5 - 5 } & Control $n=19$ & GDM $n=19$ & Control $n=20$ & GDM $n=20$ \\
\hline Age (years) & $33 \pm 4$ & $33 \pm 5$ & $33 \pm 4$ & $33 \pm 5$ \\
No. of nulliparous women & 6 & 11 & & \\
BMI $\left(\mathrm{kg} / \mathrm{m}^{2}\right)$ & $32.3(26.5-34.8)$ & $30.7(26.5-37.1)$ & $26.8(22.6-33.0)$ & $27.2(22.8-32.9)$ \\
$\%$ fat & - & - & $38.0(29.4-42.4)$ & $36.2(29.5-42.7)$ \\
WHR & - & - & $0.79(0.76-0.81)$ & $0.80^{\mathrm{a}}(0.77-0.85)$ \\
Breastfeeding (number) & - & - & 18 & 14 \\
Smokers (number) & 1 & 4 & 1 & 4 \\
Fasting glucose (mmol/1) & $4.5(4.2-4.8)$ & $5.6^{\mathrm{b}}(4.5-6.7)$ & $4.5(4.2-4.7)$ & $5.1^{\mathrm{b}}(4.5-5.5)$ \\
2-h glucose (mmol/1) & $5.7(5.2-6.3)$ & $8.8^{\mathrm{b}}(8.2-9.9)$ & $5.3(4.3-5.7)$ & $6.2^{\mathrm{b}}(5.8-8.1)$ \\
\hline
\end{tabular}


Table 2 Fasting plasma levels and dynamic IVGTT parameters in the control and GDM women

\begin{tabular}{|c|c|c|c|c|}
\hline & \multicolumn{2}{|l|}{ Pregnancy } & \multicolumn{2}{|l|}{ Postpartum } \\
\hline & Control $n=19$ & GDM $n=19$ & Control $n=20$ & GDM $n=20$ \\
\hline Fasting plasma glucose (mmol/l) & $4.5(4.1-4.8)$ & $4.5(4.1-4.7)$ & $4.8(4.6-5.1)$ & $4.7(4.6-5.4)$ \\
\hline Fasting plasma insulin $(\mathrm{mU} / \mathrm{l})$ & $12.8(6.4-14.7)$ & $11.5(9.2-15.4)$ & $6.6(5.6-10.1)$ & $7.3(5.5-11.0)$ \\
\hline$K g\left(\min ^{-1} \times 10^{-2}\right)$ & $1.59(1.47-2.04)$ & $1.28^{\mathrm{a}}(1.01-1.47)$ & $2.63(1.87-3.00)$ & $1.55^{\mathrm{a}}(1.28-2.13)$ \\
\hline $\operatorname{AIRg}\left(\mathrm{mU} \cdot 1^{-1} \cdot \min ^{-1}\right)$ & $717.0(537.0-1,007)$ & $412.7^{\mathrm{a}}(249.1-551.6)$ & $358.0(241.3-645.0)$ & $274.0(119.5-429.2)$ \\
\hline $\mathrm{SI}\left(\min ^{-1} \cdot \mathrm{mU}^{-1} \cdot 1\right)$ & $3.75(2.09-5.35)$ & $4.24(2.17-5.81)$ & $13.00(7.41-19.45)$ & $9.55^{\mathrm{a}}(3.64-14.15)$ \\
\hline $\mathrm{DI}(\mathrm{AIRg} \times \mathrm{SI})$ & $2,846(2,089-4,197)$ & $1,725^{\mathrm{a}}(671-2,980)$ & $5,125(3,280-6,307)$ & $1,995^{\mathrm{a}}(1,360-3,320)$ \\
\hline AUC insulin $40-120 \mathrm{~min}\left(\mathrm{mU} \cdot \mathrm{l}^{-1} \cdot \mathrm{min}^{-1}\right)$ & $1,024(735-1,698)$ & $1,446(1,050-1,810)$ & $623(433-815)$ & $845^{\mathrm{a}}(523-1,407)$ \\
\hline Fasting NEFA $(\mathrm{mmol} / \mathrm{l})$ & $0.518(0.389-0.627)$ & $0.561(0.445-0.638)$ & $0.525(0.394-0.665)$ & $0.445(0.401-0.562)$ \\
\hline$K_{\mathrm{NEFA}}\left(\min ^{-1}\right)$ & $2.58(1.71-3.07)$ & $1.66^{\mathrm{a}}(1.03-2.31)$ & $3.75(3.46-4.97)$ & $3.04^{\mathrm{a}}(2.03-4.40)$ \\
\hline Minimum suppressed NEFA (mmol/l) & $0.215(0.117-0.288)$ & $0.228(0.176-0.351)$ & $0.1195(0.071-0.171)$ & $0.104(0.078-0.163)$ \\
\hline$K_{\mathrm{NEFA} / \mathrm{INS}}\left(\mathrm{min}^{-1} \cdot \mathrm{mU}^{-1} \cdot 1 \cdot \mathrm{min}^{-1} \times 10^{3}\right)$ & $0.99(0.64-2.02)$ & $1.34(0.92-2.02)$ & $5.48(0.32-0.71)$ & $4.84(2.40-7.15)$ \\
\hline AUC NEFA $60-120 \mathrm{~min}\left(\mathrm{mmol} \cdot \mathrm{l}^{-1} \cdot \mathrm{min}^{-1}\right)$ & $18.8(13.4-22.5)$ & $19.3(13.2-27.2)$ & $19.8(13.4-24.1)$ & $11.9(8.2-17.1)^{\mathrm{a}}$ \\
\hline
\end{tabular}

Data are shown as medians (interquartile range)

${ }^{\mathrm{a}} p<0.025$ for GDM vs control subjects in either the pregnancy or postpartum tests

pendent variable, there were no significant differences between these associations in GDM and control subjects. Multiple regression of the above factors (insulin secretion, adiposity and glucose tolerance) and $K_{\mathrm{NEFA}}$ in all subjects revealed that in the best model, DI $(p=0.03)$ was the only independent predictor $\left(R^{2}=41.0 \%, p<0.001\right)$.
Insulin- and diet-treated GDM subjects vs control subjects Results are shown in Table 3 and Fig. 1b, c. To further explore the relationship between insulin secretion and NEFA suppression, we divided the GDM women into two groups: those who required insulin treatment for their diabetes $(n=7$; as decided by their treating clinicians, based on 2-h postprandial capillary glucose levels of above $6.5 \mathrm{mmol} / \mathrm{l}$ ) and
Fig. 1 NEFA suppression during pregnancy $(\mathbf{a}-\mathbf{c})$ and postpartum (d-f) in GDM ( $\square$ ) and control ( $)$ subjects in the whole group $(\mathbf{a}, \mathbf{d})$, in insulin-treated GDM vs matched control subjects $(\mathbf{b}, \mathbf{e})$ and in diet-treated GDM vs matched control subjects $(\mathbf{c}, \mathbf{f})$
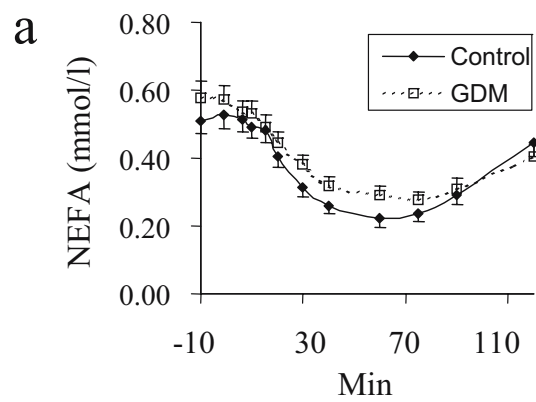

b

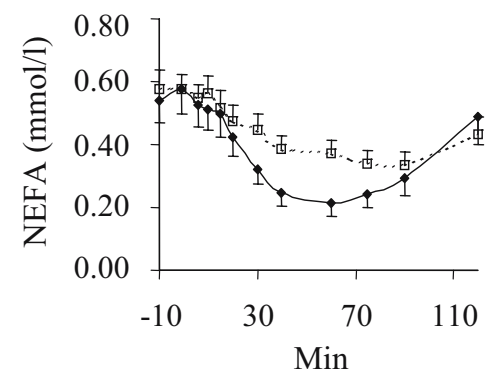

C

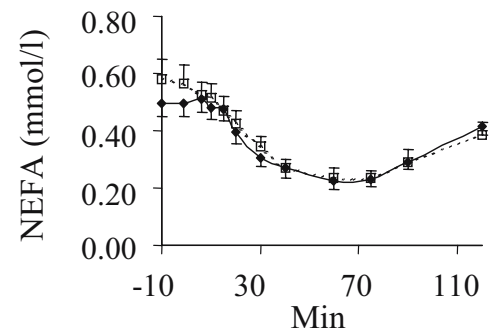

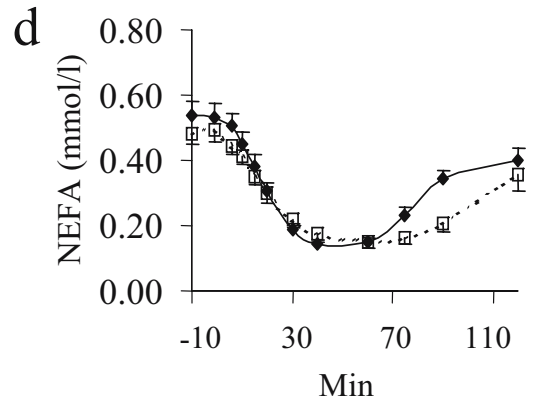
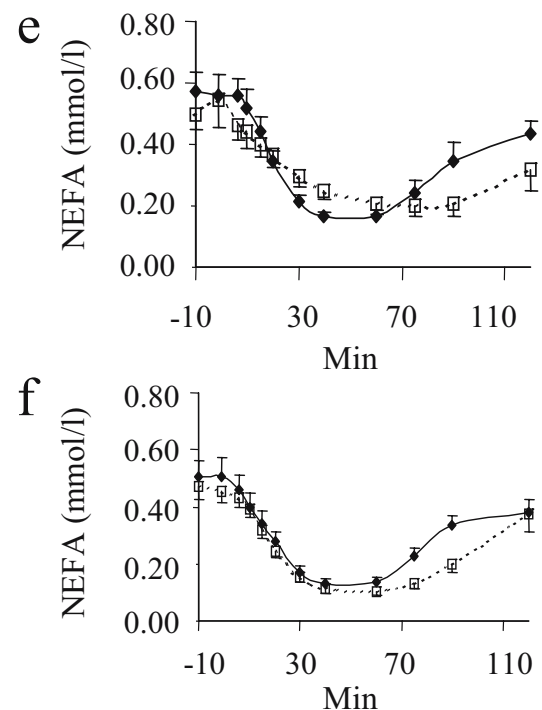
Table 3 IVGTT results comparing insulin- and diet-treated GDM with their matched control subjects

\begin{tabular}{lllll}
\hline & Insulin-treated GDM subjects & Control subjects & Diet-treated GDM subjects & Control subjects \\
\hline In pregnancy & $n=7$ & $n=7$ & $n=12$ & $n=12$ \\
BMI $\left(\mathrm{kg} / \mathrm{m}^{2}\right)$ & $35.1^{\mathrm{a}}(33.2-37.8)$ & $33.5(32.3-34.8)$ & $26.9(25.5-32.0)$ & $27.8(25.7-34.6)$ \\
$\mathrm{Kg}\left(\mathrm{min}^{-1} \times 10^{-2}\right)$ & $1.18(0.88-1.51)$ & $1.53(1.39-1.89)$ & $1.37(1.22-1.49)$ & $1.8(1.49-2.29)$ \\
$\mathrm{AIRg}\left(\mathrm{mU} \cdot 1^{-1} \cdot \mathrm{min}^{-1}\right)$ & $256^{\mathrm{a}}(158-380)$ & $984^{\mathrm{b}}(832-1,579)$ & $500(395-817)$ & $631(487-858)$ \\
$\mathrm{SI}\left(\mathrm{min}^{-1} \cdot \mathrm{mU}^{-1} \cdot 1\right)$ & $4.12(1.24-5.26)$ & $3.25(1.80-3.78)$ & $4.37(2.39-6.12)$ & $5.07(3.15-7.74)$ \\
$\mathrm{DI}(\mathrm{SI} \times \mathrm{AIRg})$ & $632^{\mathrm{a}}(363-1,565)$ & $2,846(2,089-3,202)$ & $2,664(1,624-3,402)$ & $3,387(2,311-4,350)$ \\
$K_{\mathrm{NEFA}}\left(\mathrm{min}^{-1} \times 10^{-2}\right)$ & $1.06^{\mathrm{a}}(1.52-0.63)$ & $2.83^{\mathrm{b}}(3.22-2.27)$ & $2.07(3.17-1.50)$ & $2.10(3.02-1.48)$ \\
Postpartum & $n=8$ & $n=8$ & $n=12$ & $n=12$ \\
$\mathrm{BMI}\left(\mathrm{kg} / \mathrm{m}^{2}\right)$ & $30.1(26.0-33.2)$ & $29.9(23.3-33.7)$ & $24.6(22.2-32.4)$ & $25.1(22.5-33.0)$ \\
$K \mathrm{Kg}\left(\mathrm{min}^{-1} \times 10^{-2}\right)$ & $1.35(1.08-1.60)$ & $2.33^{\mathrm{b}}(1.82-3.02)$ & $1.95(1.45-2.63)$ & $2.77(2.10-3.00)$ \\
$\mathrm{AIRg}\left(\mathrm{mU}^{-1} \cdot \mathrm{min}^{-1}\right)$ & $176(101-323)$ & $508^{\mathrm{b}}(326-842)$ & $312(196-609)$ & $247(233-361)$ \\
$\mathrm{SI}\left(\mathrm{min}^{-1} \cdot \mathrm{mU}^{-1} \cdot 1\right)$ & $9.64(3.81-13.15)$ & $8.16(6.73-14.05)$ & $6.77(3.39-16.40)$ & $16.60^{\mathrm{b}}(11.60-20.80)$ \\
$\mathrm{DI}(\mathrm{SI} \times \mathrm{AIRg})$ & $1,550(1,140-2,345)$ & $5,160^{\mathrm{b}}(3,110-6,080)$ & $2,490(1,840-5,490)$ & $5,010(3,670-6,330)$ \\
$K_{\mathrm{NEFA}}\left(\mathrm{min}^{-1} \times 10^{-2}\right)$ & $2.01^{\mathrm{a}}(1.29-2.87)$ & $3.70^{\mathrm{b}}(3.56-4.88)$ & $4.24(3.52-5.43)$ & $4.03(3.25-4.97)$ \\
\hline
\end{tabular}

${ }_{p}^{a} p \leq 0.01$ for insulin-treated GDM subjects vs diet-treated GDM subjects

${ }^{\mathrm{b}} p<0.025$ for GDM vs control subjects in each subgroup in pregnancy or postpartum

those who did not $(n=12)$. The insulin-treated GDM women had markedly reduced AIRg (by $\sim 75 \%$ ) compared with their matched control subjects. In contrast, this was not evident in the diet-treated GDM group. The NEFA suppression of the insulin-treated group was also markedly reduced (Fig. 1b), whereas the NEFA suppression of the diet-treated GDM subjects was similar to that of their matched control subjects (Fig. 1c). The overall difference in NEFA kinetics observed between GDM and control groups was therefore due solely to the GDM subjects who required insulin in pregnancy and had the severest deficiency in AIRg.

\section{Studies postpartum}

Baseline results In the GDM group postpartum, one subject had diabetes at the 6-week OGTT and four had IGT; the remainder had NGT.

Insulin sensitivity and secretion Results are shown in Table 2. Former GDM women had defects in insulin secretion and action, with significantly lower SI and DI, and higher IVGTT insulin AUC from 40 to 120 min than their control counterparts.

NEFA suppression Results are shown in Fig. 1d. Regression analysis of the NEFA values from 15 to $40 \mathrm{~min}$ demonstrated a significant difference between GDM and control subjects over time $(p<0.01)$, with GDM subjects having slower suppression of NEFA.

Once again, to determine which metabolic factors were associated with $K_{\mathrm{NEFA}}$, univariate analysis revealed that postpartum $K_{\mathrm{NEFA}}$ correlated with measures of insulin secretion (AIRg: $r=0.48, p=0.002$, DI: $r=0.53, p<0.001$ ) and glucose tolerance $(\mathrm{Kg}: r=0.45, p=0.004$, fasting glucose
OGTT: $r=-0.37, p=0.02)$, but not with SI $(r=0.07$, $p=0.67)$ or BMI $(r=-0.001, p=0.99)$. Apart from the relationship between $K_{\mathrm{NEFA}}$ and $\left(l_{\mathrm{n}}\right)$ fasting glucose OGTT ( $p=0.002)$, linear regression with $K_{\mathrm{NEFA}}$ as the dependent variable revealed no differences in these associations between control and GDM groups. Multiple regression of $K_{\mathrm{NEFA}}$ (including measures of insulin secretion, adiposity and glucose tolerance as dependent variables) for all subjects revealed the independent predictors were $\left(l_{n}\right) \mathrm{AIRg}$ and $\left(l_{n}\right)$ fasting OGTT glucose $\left(R^{2}=31.4 \%\right.$ for this model, $p<0.001)$.

Insulin- and diet-treated GDM subjects vs control subjects Results are shown in Table 3. The former insulin-treated GDM subjects had significant reductions in AIRg and disposition index, but not in SI, compared with their matched control subjects.

The NEFA suppression curves of the former insulintreated GDM subjects vs their matched control subjects are illustrated in Fig. 1e. Again, the subjects requiring insulin were responsible for the reduced NEFA suppression of the overall GDM group. When the NEFA suppression of the former GDM women with NGT $(n=15)$ was examined, the GDM women did not have significantly different NEFA suppression (GDM: $K_{\mathrm{NEFA}} 3.65 \pm 0.46$ vs control: $3.89 \pm 0.25 \mathrm{~min}^{-1}$ ). Of note, all but one of the GDM subjects with impaired glucose handling were insulin treated, thus the GDM group with NGT was very similar to the diet-treated GDM group.

Finally, we noted that, postpartum, the late rebound of NEFA ( $>40$ min post glucose load) was slower in the GDM subjects (Fig. 1d-f), with a reduced AUC for NEFA 60-120 min (Table 2). In addition, NEFA AUC (60-120 min) correlated with insulin AUC $(40-120 \mathrm{~min})(r=-0.56$, $p<0.001)$ in all subjects. 


\section{Discussion}

We have characterised the carbohydrate and lipid defects in a group of GDM women compared with BMI-matched healthy women, both in pregnancy and postpartum.

The novel finding of this study is that, in GDM subjects, impaired NEFA suppression to endogenous insulin secretion occurred in pregnancy and persists postpartum. This defect of NEFA suppression was limited to the GDM subjects with the most severe defect in endogenous insulin secretion, which was underscored by $K_{\mathrm{NEFA}}$ correlating with measures of insulin secretion rather than insulin resistance. Previous studies have demonstrated impaired NEFA suppression to exogenous insulin in a clamp situation among pregnant GDM subjects [5, 24], which presumably represents resistance to the anti-lipolytic action of insulin on the adipocyte. In our subjects, $K_{\mathrm{NEFA}}$ normalised to the amount of insulin secreted $\left(K_{\mathrm{NEFA} / \mathrm{INS}}\right)$ was not different between GDM and control subjects in pregnancy or postpartum, which supports the importance of insulin secretion in determining NEFA suppression.

Insulin treatment was used as a marker of the magnitude of the beta cell deficiency in the pregnant women (although we acknowledge that the decision to commence insulin also depends upon patient dietary compliance), which was confirmed by the postpartum OGTT results where four of the five women with IGT had required insulin during pregnancy. Comparison of the metabolic characteristics of the insulin-treated and diet-treated subgroups shows that it is the difference in AIRg, and not in SI, that accounts for the difference in NEFA suppression. This is highlighted in the postpartum data, where the diet-treated GDM subjects had similar NEFA suppression to their control counterparts, despite having a significantly reduced SI.

Subjects were deliberately pair matched for age and BMI in order to identify defects that were independent of total body adiposity. Previous studies have employed statistical adjustments of SI and AIRg to BMI [3]. Given that the BMI is higher in GDM subjects, and adiposity is a risk factor for GDM [25] and type 2 diabetes, matching subjects for BMI and adiposity may remove the metabolic differences between our study populations. Nevertheless, our data still show significant differences in SI and AIRg between the groups, even when the data are adjusted for the higher central adiposity (WHR) in our GDM subjects.

Finally, the GDM subjects postpartum demonstrated lower NEFA levels after $40 \mathrm{~min}$ and a slower return to basal fasting NEFA levels, with a significantly reduced AUC from 60 to $120 \mathrm{~min}$. This has been observed previously [3], and may be due to higher insulin levels (as expressed by insulin AUC for 40-120 min, and suggested by the positive correlation between insulin AUC and NEFA AUC), in the former GDM subjects in the latter part of the IVGTT.

In conclusion, we have documented abnormal NEFA suppression to endogenously secreted insulin in GDM subjects with significant beta cell dysfunction. The abnormal NEFA suppression persisted postpartum in the most insulin-deficient GDM subjects, which was independent of SI.
Acknowledgements This work was supported by the National Health and Medical Research Council of Australia, the Medical Research Foundation for Women and Babies, a Cardiovascular Lipid Research Grant and a Novo Nordisk Regional Diabetes Support Scheme Grant. The authors also thank our research nurse Noella Johnson and the women who participated.

\section{References}

1. Oats J, Beischer N (1986) Gestational diabetes. Aust N Z J Obstet Gynaecol 26:2-10

2. Bergman RN, Ader M, Huecking K, Van Citters G (2002) Accurate assessment of beta-cell function: the hyperbolic correction. Diabetes 51(Suppl 1):S212-S220

3. Kousta E, Lawrence NJ, Godsland IF et al (2003) Insulin resistance and beta-cell dysfunction in normoglycaemic European women with a history of gestational diabetes. Clin Endocrinol (Oxf) 59:289-297

4. Ward WK, Johnston CL, Beard JC, Benedetti TJ, Halter JB, Porte D Jr (1985) Insulin resistance and impaired insulin secretion in subjects with histories of gestational diabetes mellitus. Diabetes 34:861-869

5. Catalano PM, Nizielski SE, Shao J, Preston L, Qiao L, Friedman JE (2002) Downregulated IRS-1 and PPARgamma in obese women with gestational diabetes: relationship to FFA during pregnancy. Am J Physiol: Endocrinol Metab 282:E522E533

6. Homko CJ, Sivan E, Reece EA, Boden G (1999) Fuel metabolism during pregnancy. Semin Reprod Endocrinol 17:119125

7. Meyer B, Calvert D, Moses R (1996) Free fatty acids and gestational diabetes mellitus. Aust N Z J Obstet Gynaecol 36:255-257

8. Charles MA, Eschwege E, Thibult N et al (1997) The role of non-esterified fatty acids in the deterioration of glucose tolerance in Caucasian subjects: results of the Paris Prospective Study. Diabetologia 40:1101-1106

9. Boden G (1997) Role of fatty acids in the pathogenesis of insulin resistance and NIDDM. Diabetes 46:3-10

10. Kashyap S, Belfort R, Gastaldelli A et al (2003) A sustained increase in plasma free fatty acids impairs insulin secretion in nondiabetic subjects genetically predisposed to develop type 2 diabetes. Diabetes 52:2461-2474

11. Jensen CB, Storgaard H, Holst JJ, Dela F, Madsbad S, Vaag AA (2003) Insulin secretion and cellular glucose metabolism after prolonged low-grade intralipid infusion in young men. J Clin Endocrinol Metab 88:2775-2783

12. Carpentier A, Mittelman S, Bergman R, Giacca A, Lewis G (2000) Prolonged elevation of plasma free fatty acids impairs pancreatic b-cell function in obese nondiabetic humans but not in individuals with type 2 diabetes. Diabetes 49:399-408

13. Paolisso G, Gambardella A, Amato L et al (1995) Opposite effects of short and long term fatty acid infusion on insulin secretion in healthy subjects. Diabetologia 38:1295-1299

14. Hoffman L, Nolan C, Wilson JD, Oats JJ, Simmons D (1998) Gestational diabetes mellitus - management guidelines. The Australasian Diabetes in Pregnancy Society. Med J Aust 169:93-97

15. Boston RC, Stefanovski D, Moate PJ, Sumner AE, Watanabe RM, Bergman RN (2003) MINMOD Millennium: a computer program to calculate glucose effectiveness and insulin sensitivity from the frequently sampled intravenous glucose tolerance test. Diabetes Technol Ther 5:1003-1015

16. McNair PD, Colman PG, Alford FP, Harrison LC (1995) Reproducibility of the first-phase insulin response to intravenous glucose is not improved by retrograde cannulation and arterialization or the use of a lower glucose dose. Diabetes Care 18:1168-1173 
17. Lerner RL, Porte D Jr (1971) Relationship between intravenous glucose loads, insulin responses and glucose disappearance rate. J Clin Endocrinol Metab 33:409-417

18. Albano JD, Ekins RP, Maritz G, Turner RC (1972) A sensitive, precise radioimmunoassay of serum insulin relying on charcoal separation of bound and free hormone moieties. Acta Endocrinol (Copenh) 70:487-509

19. Cutfield WS, Bergman RN, Menon RK, Sperling MA (1990) The modified minimal model: application to measurement of insulin sensitivity in children. J Clin Endocrinol Metab 70:1644-1650

20. Henriksen JE, Alford F, Vaag A, Handberg A, Beck-Nielsen H (1999) Intracellular skeletal muscle glucose metabolism is differentially altered by dexamethasone treatment of normoglycemic relatives of type 2 diabetic patients. Metabolism 48:1128-1135
21. Jensen MD, Caruso M, Heiling V, Miles JM (1989) Insulin regulation of lipolysis in nondiabetic and IDDM subjects. Diabetes 38:1595-1601

22. Bolinder J, Kager L, Ostman J, Arner P (1983) Differences at the receptor and postreceptor levels between human omental and subcutaneous adipose tissue in the action of insulin on lipolysis. Diabetes 32:117-123

23. Ader M, Bergman RN (1994) Importance of transcapillary insulin transport to dynamics of insulin action after intravenous glucose. Am J Physiol 266:E17-E25

24. Xiang AH, Peters RK, Trigo E, Kjos SL, Lee WP, Buchanan TA (1999) Multiple metabolic defects during late pregnancy in women at high risk for type 2 diabetes. Diabetes 48:848-854

25. Solomon CG, Willett WC, Carey VJ et al (1997) A prospective study of pregravid determinants of gestational diabetes mellitus. JAMA 278:1078-1083 